\title{
INTERVENTION APPROACHES IN PHYSICAL EDUCATION IN ORDINARY SCHOOL TO ENHANCE SOCIAL INTERACTION IN A STUDENT WITH AUTISTIC SPECTRUM DISORDER: A CASE STUDY
}

\author{
Maria Markaki ${ }^{1}$, \\ Nikoleta Chyta ${ }^{2}$, \\ Georgia Maggouritsa ${ }^{1 \mathrm{i}}$, \\ Dimitrios Kokaridas ${ }^{1}$ \\ ${ }^{1}$ Department of Physical Education and Sport Science, \\ University of Thessaly, \\ Greece \\ ${ }^{2}$ School of Primary Education, \\ Athens, \\ Greece
}

\begin{abstract}
:
Co-education of students with Autistic Spectrum Disorder (ASD) during the lesson of Physical Education (PE) in the Greek School constitutes contemporary educational reality. However, its success depends on many factors, with the most important being the effective employment of cooperative physical education methods for students with disabilities or no disabilities. The purpose of this case study was to analyze the impact of a physical education intervention program on the reinforcement of the social interaction of a student with ASD, aged 10, in the ordinary school. The intervention exercise program included the following specific educational approaches and intervention strategies: a) game with the support of an adult (adult support game) b) integrated playgroups with guided involvement (Integrated Play Groups Model) and c) games between peers providing a model to imitate. The duration of the program was eight weeks, with a frequency of three times per week, each lesson of PE (Physical Education) lasting 45 minutes. The data collection tools that were used in the pre-intervention program were the semi-structured interview and the «Autism Social Skills Profile» scale (Bellini \& Hopf, 2007), which was adapted in the Greek Language by Syriopoulou- Delli, Agaliotis and Papaefstathiou (2016). It was used before and after the intervention. The results of the research study showed that the student with ASD had positive experiences through his relationship with his classmates, increased his level of participation in the lesson of Physical Education (PE) throughout the implementation of the intervention program, and improved his social reciprocity through interaction and collaboration with his peers, without displaying improper or detrimental social behavior patterns.
\end{abstract}

i Correspondence: email gmag@uth.gr 
Keywords: integration, physical education, intervention strategies, social interaction, Autistic Spectrum Disorder (ASD)

\section{Introduction}

Autism is included in the Pervasive Developmental Disorder (PDD) category. It is characterized by severe lack in many development areas at the same time, which justifies the characterization of Pervasive Disorder. The clinical picture varies in reactions and importance. Nevertheless, the main characteristics are common in every form of the syndrome, such as social contact and interaction disorder and limited, unusual, repetitive behaviors and interests (American Psychiatric Association, 2013). The distinct characteristics and criticality of the cognitive deficits and deviations, the reason and the treatment of these disorders serve as a challenge for children and adults with Autistic Spectrum Disorder, specialists, parents and competent bodies that deal with these specific cases (Faras, Al Ateeqi \& Tidmarsh, 2010). One of the most identifiable characteristics of children with ASD is the backwardness and the deficits they show in the frequency, the type and the quality of social interaction and social relations with other children in their environment having as a result, the formation of social difficulties, which affect their social adjustment (Hendricks \& Wehman, 2009; Tutt, Powell \& Thornton, 2006). The available research findings indicate that the social relations of children with autism are not sustainable because there is a lack of understanding regarding the expressions, the emotions and the body language (Cox et al., 2013).

Furthermore, children with ASD face difficulty in comprehending non-verbal communication and social messages. Also, they fail in understanding and using social rules (Jordan, 2005b), and quite often, they show provocative non-verbal social behaviors such as self-isolation, self-harming or aggression (Walton \& Ingersoll, 2013).

Inclusion is a procedure that aims to improve every child's educational experience by increasing their involvement in the educational programs, culture, and community of ordinary schools (Ainscow, Dyson, \& Weiner, 2013). Intervention for children with ASD is mainly educational and broadly aims at the socialization and personal advancement of the child, the development of communication and externalization of their needs, wishes, and feelings verbally or non-verbally (Booth \& Ainscow, 2011). The thorough Special Education Program for children with autism provides sufficient instructions and educational practices regarding the socialization of these children in ordinary schools. However, the educational reality seems to be hard for teachers who try to cope with educational aims and students with ASD who seek isolation because of their symptoms. As a result, integration for children with autism in communication and learning needs adaptations as far as the detailed syllabus is concerned, the teaching methods and the classroom environment (Klavina, Jerlinder, Kristén, Hammar \& Soulie, 2014).

Quite a few studies, up until today, have mentioned cognitive, social and physical benefits relating to regular exercise for individuals with ASD (Ferreira et al., 2018; Lee \& Vargo, 2017). Nevertheless, participation in such activities is often a challenge for 
children with ASD because of their poor kinetic functions and the absence of essential motives to involve themselves in any form of physical activity (Pan, 2014; Srinivasan, Pescatello, \& Bhat, 2014). Therefore, inclusion for children with autism in the ordinary school and especially in the lesson of Physical Education requires systematic intervention strategies which promote team and collaborative play and aim at social interaction for children with autism (Ali \& Frederickson, 2006; Reynhout \& Carter, 2006).

Such successful approaches are play supported by an adult (adult support game) (Sheratt, 2002), integrated playgroups (Integrated Play Groups Model) (Wolfberg, 2016) and mediation in peer couples that provide a model to imitate (peer-mediated interventions) (Chan et al., 2009). All the above approaches require appropriate organization of the workout area, suitable material-technical infrastructure, the creation of a consistent program and routine, the use of visual instructions, high-level guidance, and the use of boosters to improve the behavior of a child with ASD and the reinforcement of the student's social interaction (Tyler, Mac Donald \& Menear, 2014). At this point, we must highlight the contribution of this case study to the social interaction improvement for a child with ASD since a literature review has shown that there has not been any research action regarding the implementation of such intervention strategies in the PE lesson in our country.

This research aimed to present the impact of a PE intervention program on the ordinary school, on social interaction reinforcement, for a student with ASD based on suitable intervention strategies.

\section{Material and Methods}

\subsection{Sample}

This research study was a case study in which a student with ASD aged ten, who went to the $4^{\text {th }}$ grade of the elementary school in the district of Trikala, joined an exercise intervention program after having the parents sign the consent form.

\subsection{Measurement instruments}

For this research study, the «Autism Social Skills Profile» (Bellini \& Hopf, 2007) scale was used, which was adapted in the Greek language by Syriopoulou-Delli, Agaliotis $\kappa \alpha$ เ Papaefstathiou (2016). It is a reliable tool that has been used in many studies (Liu, Kaarengala, \& Litchke, 2019; Papaefstathiou \& Syriopouloy-Delli, 2014). It assesses the social functionality of teenagers with ASD aged 6 to 17 and includes 49 questions that evaluate the demonstration frequency of behaviors that the student expresses during his social interactions. The calculation of the questions is done with the 4 Likert Scale ( $0=$ never, $1=$ sometimes, $2=$ often, $3=$ quite often) with the high scores showing positive social behaviors. Regarding their type, the questions are sorted into three factors that have to do with "social reciprocity" (26 questions), "social involvement/avoidance" (14 questions) and "detrimental social behaviors" (9 questions). Some questions are of a negative direction and have been reversed to positive for the needs of the evaluation. 
Next, the total score of these three factors is added and the participant's level of social skills is extracted, based on the total score that the student achieves (high- score 147).

The information used to fill in the scale was collected through a semi-structured interview of the child's teachers (parallel support teacher and PE teacher). This procedure displayed a detailed image of the social functionality of the child with ASD and helped develop teaching and educational goals. Specifically:

The semi-structured interview with the parallel support teacher and the PE teacher aimed to make the teaching planning and the teaching intervention easier by collecting data through these seven questions.

Do you believe that the student:

1) Shows ability to work on his own?

2) Shows ability to work with other classmates close to him?

3) Completes the PE activities or denies joining in the lesson?

4) Expresses behavior problems (frustration, anger) during the coaching?

5) Waits for his turn during team activities? And if he does, does he follow instructions and rules?

6) Participates in team activities by imitating others?

7) Adjusts to changes and accepts changes during the PE lesson?

\subsection{Procedure}

The pre-intervention phase included: a) A semi-structured interview with the parallel support teacher and the PE teacher so that detailed information regarding the student's progress up to that point could be collected, together with a brief case history of the student. b) The filling in of the «Autism Social Skills Profile» (Bellini \& Hopf, 2007), from the researcher in collaboration with the two teachers, adapted in the Greek language by Syriopoulou-Delli, Agaliotis and Papaefstathiou (2016).

Intervention exercise program: the intervention exercise program took place in the school's PE hall and lasted eight weeks. There was a 45-minute lesson three times a week. Each class was based on specific intervention strategies, which included:

a) Play with the support of an adult (Sheratt, 2002). (Adult support game). The planning of the first (5) five lessons included kinesthetic skills that had to do with the body's orientation in the room, visual-motor coordination, static and dynamic balance, lateral movement. The general goal was the student's participation in most activities of the daily program with the support of an adult. The lessons' activities had difficulty levels and the sub-objectives were the student with ASD to follow simple instructions and apprehend the beginning and the termination of an activity with the help of visual stimuli (photographs, transmission cards).

b) Games between peers providing a model to imitate (peer-mediated interventions) (Chan et al., 2009). The following five (5) lessons of the intervention program included teaching natural skills, mainly through pair activities that had to do with flexibility, strength and aerobic capacity. The general goal was peer-mediated teaching. Each lesson had activity stations and during each class, we made sure that the couples changed so that the student 
with ASD could learn to cope with changes in people, something that he lacked, to develop proximity and improve interpersonal relations with his classmates.

c) Integrated playgroups with guided participation (Integrated Play Groups Model with guided participation) (Wolfberg, 2016). The following five (5) lessons included cooperation team games. There were adaptations in the equipment and the rules. The student with ASD was placed in a small group with his classmates, who would provide verbal and kinesthetic guidance to carry out the exercises. The selection of the specific synergetic games had multiple goals like learning to wait for his turn, sharing objects and stuff in a structured exercise environment, and following each activity's rules.

d) Combination of the techniques for peer couples and the participation exercises for integrated playgroups in specific sports. The following six (6) lessons included the teaching of basic basketball skills (two teaching hours), the teaching of basic football skills (two teaching hours), and the teaching of basic track and field skills (two teaching hours). These specific teaching styles were carried out by switching between teaching methods since the first lesson of each sport was accomplished by assigning the students in couples, while the second lesson was achieved by integrating the student into a specific group of four with his classmates. During these particular lessons, the students could choose from a variation of the same exercise with a different difficulty level. The primary goal was, on the one hand, to improve the skills that are essential for these specific sports in a playful way and, on the other hand, to develop a collaboration and teamwork spirit and finally the student with ASD to be able to follow new instructions and take the initiative on how to carry out each activity. The last three (3) lessons included the cultivation of the movement rhythm, with elements that had to do with the knowledge of the concepts 'slowly-quickly', 'simultaneously-successively', 'acceleration- deceleration'. The teaching goal was to improve his eye contact, imitate his classmates, learn to wait for his turn, and relax through music-kinetic activities to reduce stereotypical moves that he usually displayed because of his anxiety or external noises. All this was done by assigning the students in couples and integrating the student into a small group.

Post-intervention phase: During the post-intervention phase, a final evaluation of the student's social skills with ASD was made. The evaluation was made by filling anew the «Autism Social Skills Profile» (Syriopoulou-Delli, Agaliotis and Papaefstathiou, 2016), in order to showcase the student's progress, in case of potential changes to the grade of his social interactions as well as an appraisal of his initial goals.

Results analysis: The analysis included descriptive analysis of the three «Autism Social Skills Profile» (Syriopoulou-Delli, Agaliotis and Papaefstathiou, 2016) factors, before and after the intervention and a quality approach of the semi-structured interview results.

\section{Results}

The first thing was to collect the data from the semi-structured interview from both instructors. The goal of the questions was to obtain a primary and deep understanding 
of both instructors' perception over the degree of cooperation, behavior and social skill of the student while at school. The qualitative results that included typical expressions of the instructors about the child's abilities are presented as follows:

Question 1: Does the student display ability to work on his own?

Both instructors answered that, regarding the learning effort, the student could work on an activity by himself, standing or sitting without bothering others next to him. The parallel support teacher distinctly mentioned, "During the PE lesson, but also in his free time the student usually prefers to play alone while his classmates play beside him".

Question 2: Does the student display collaboration ability with other classmates?

The PE teacher distinctly mentioned, "Usually he works with the parallel support teacher, in the same room as the rest of his classmates". While the parallel support teacher noted, "He is a quite cooperative child who prefers to work with two specific classmates of his who help him sufficiently, all though his classmates try to include him in the activities and help him".

Question 3: Does the student complete the PE exercises, or does he refuse to be part of the lesson?

Both instructors answered that the student usually does not complete the activities during the PE lesson, and only through kinesthetic help he can participate in some of them. The parallel support teacher specifically mentioned, "His attention is often disrupted mainly by noises or movements from others that work or play beside him. As a result, his participation in the activities is stopped".

Question 4: Does the student display behavioral problems (frustration, anger) during the coaching?

Both instructors emphatically answered ' $\mathrm{No}^{\prime}$, and specifically, the PE teacher mentioned, "He is a kind and polite kid who usually takes the initiative to hug you". While the parallel support teacher noted, "He doesn't cause any problems, is pretty friendly with others, and even when he is careless, he will apologize to others".

Question 5: Does the student wait for his turn in team activities? And if he does, does he follow the instructions and rules?

According to the answers from both instructors, the student shows an inability to wait for his turn in group activities with one or more familiar persons since he leaves the line and touches others. However, through often suggestions from his teachers, he is in the position to follow verbal instructions and abide by the game's rules. As the parallel support teacher mentioned, "You will have to explain something to him twice in order to comprehend it". 
Question 6: Does he participate in group activities by imitating others?

Both instructors answered that the student does not show mobility difficulties and can participate in group activities by imitating others as long as there have been suitable adaptations in the teaching environment. As the parallel support teacher distinctly mentioned, "He can imitate and share stuff with others as long as the teaching environment is strictly structured".

Question 7: Does he adjust and bear with changes during the PE lesson?

Based on both instructors' answers, it is easily understood that the student adjusts to the changes that have to do with the schedule, the equipment, the activities and space. However, he cannot abide changes in the persons since he wishes to interact with specific classmates he socializes with outside of school. Specifically, the parallel support teacher mentioned, "In the first place, it would help to include the student in a specific group of his classmates who he considers his friends, and they know how to help him better".

Summarizing the semi-structured interview results, it is evident that both instructors' answers regarding the learning effort, behavior, and interaction of the student with ASD matched. Both instructors placed emphasis on the fact that the student needs constant kinesthetic guidance and frequent suggestions in order to follow the rules and instructions during the PE lesson. He finds it hard to comprehend role reversals and wait for his turn to join the game, and he stays on the team for a short time as his attention is frequently interrupted. However, the student is in the position to imitate others and pass objects to the individuals around him in a structured teaching environment and wishes to collaborate with specific classmates of his.

\subsection{Descriptive analysis of the three «Autism Social Skills Profile» factors before and after the intervention}

Regarding the social reciprocity factor that assesses the essential skills for the continuation of successful interactions, it is noticed that in the initial assessment, the score was equal to 35.00 , with the highest possible being $(\mathrm{H}=78.00)$. The question with the highest score was the statement, "The student engages himself with personal hygiene". In contrast, the questions with the lowest score were the statements "The student expresses his feelings", "Plays when it is his turn", "Pays compliments to others", "Knows about other people's interests" and "Identifies non-verbal signs or body language". In the final assessment, the student increased the score to 52.00. The questions with the highest score were the statements "The student plays when it is his turn", "Engages himself with personal hygiene", "Acknowledges compliments from others", "Keeps suitable distance when he interacts with peers", "Recognizes the facial expressions of others", "Recognizes the body language of others", "Responds to the greetings of others", "Responds to questions directed at him/her" and "Offers his help to others". On the contrary, the questions with the lowest score were the statements "Knows about other people's interests", "Provides compliments to others", "Takes the initiative to greet someone", "Asks questions in order to be informed about a subject", "Asks 
questions in order to be informed about a person", "Empathizes with other people's problems" and "Takes into account the different aspects of a subject". (Bar chart $1 \& 2$ ).

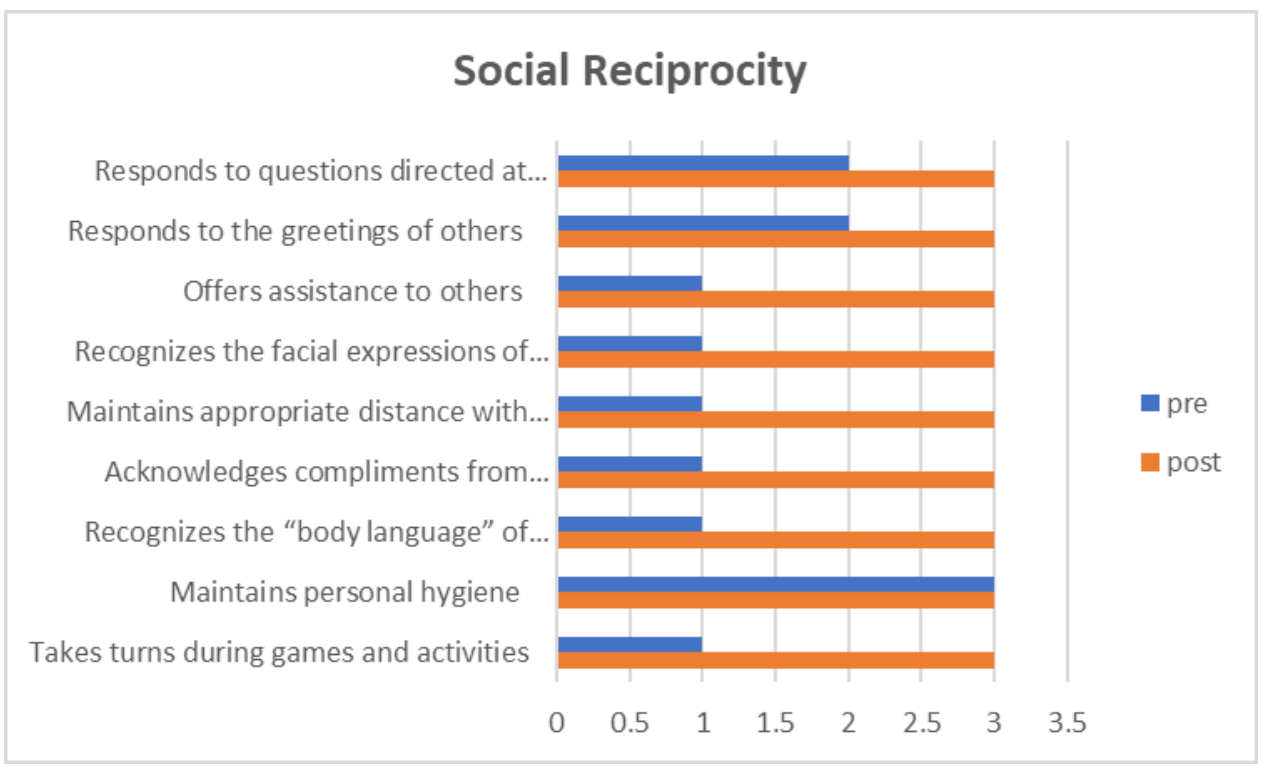

Bar chart 1: Social Reciprocity factor (Pre \& Post-reading)

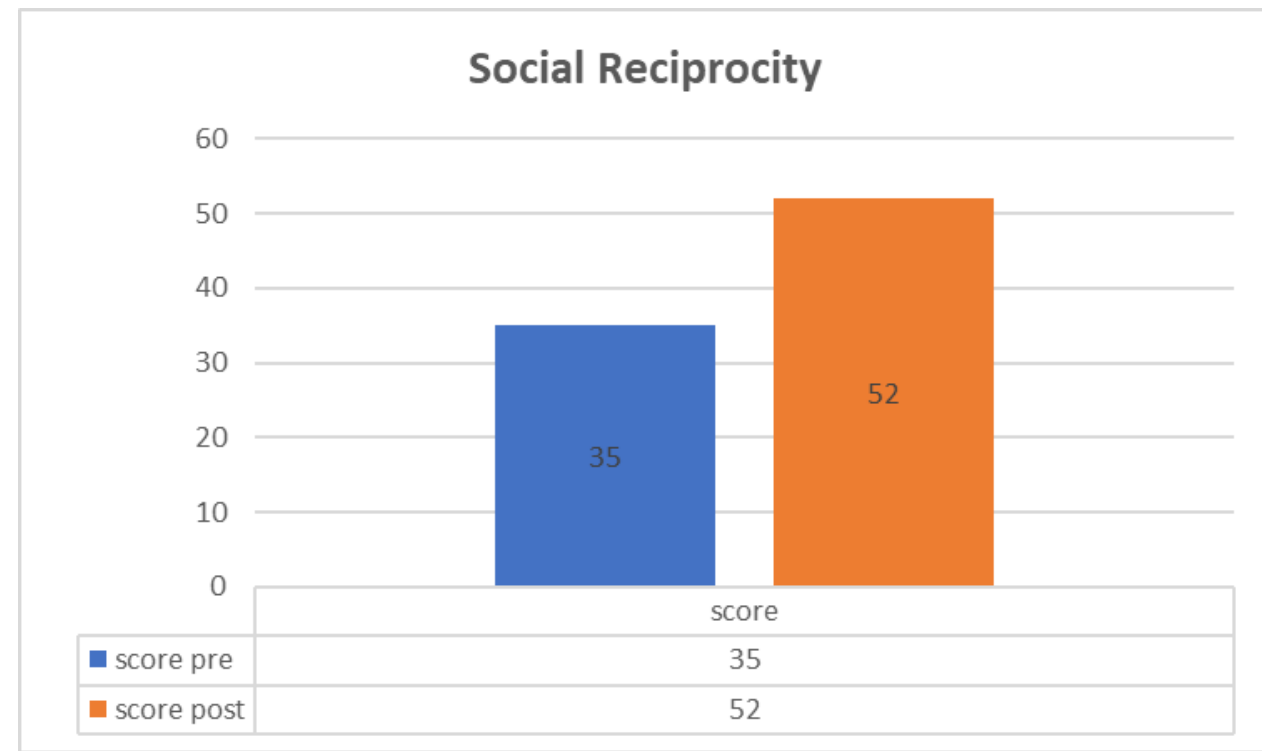

Bar chart 2: Social Reciprocity factor (Total score of Pre \& Post-reading)

Regarding the social participation/avoidance factor that assesses the frequency in which the student with ASD shows participation or avoidance in social interaction, it was noticed that in the initial evaluation, the score was equal to 19.00, with the highest possible being $(\mathrm{H}=42.00)$. The questions with the highest score were the statements "The student has positive experiences from his relationships with his peers" and "Involves himself in social interactions with one of his peers". On the contrary, the questions with the lowest score were the statements "The student interacts with his peers during structured activities", "Interacts with peer groups" and "Asks others to help him". In the final assessment, the student with ASD totaled a score that was equal to 35.00. The 
questions with the highest score were the statements "The student is not afraid of social interactions", "Allows others to help him", "Has positive experiences from his relationships with his peers", "Does not get involved in individual activities while being with peers", "Engages in positive peer interactions", "Interacts with peers during structures activities" and "Accepts his peers' invitations to join them in activities". On the contrary, the questions with the lowest score were the statements "The student asks others to help him", "Invites his peers to participate in activities" and "Involves himself in individual activities". (Bar chart $3 \& 4$ ).

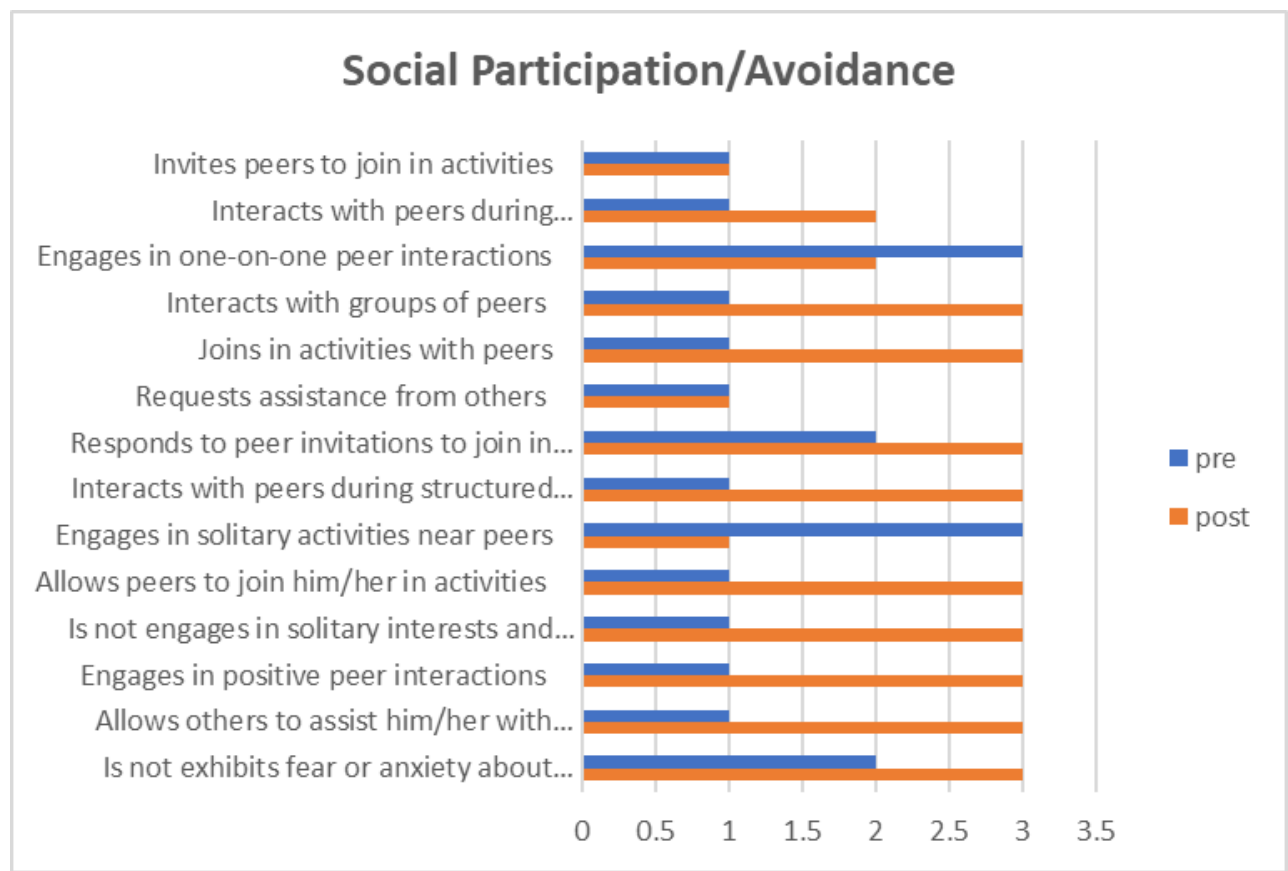

Bar chart 3: Social Participation / Avoidance factor (Pre \& Post-reading)

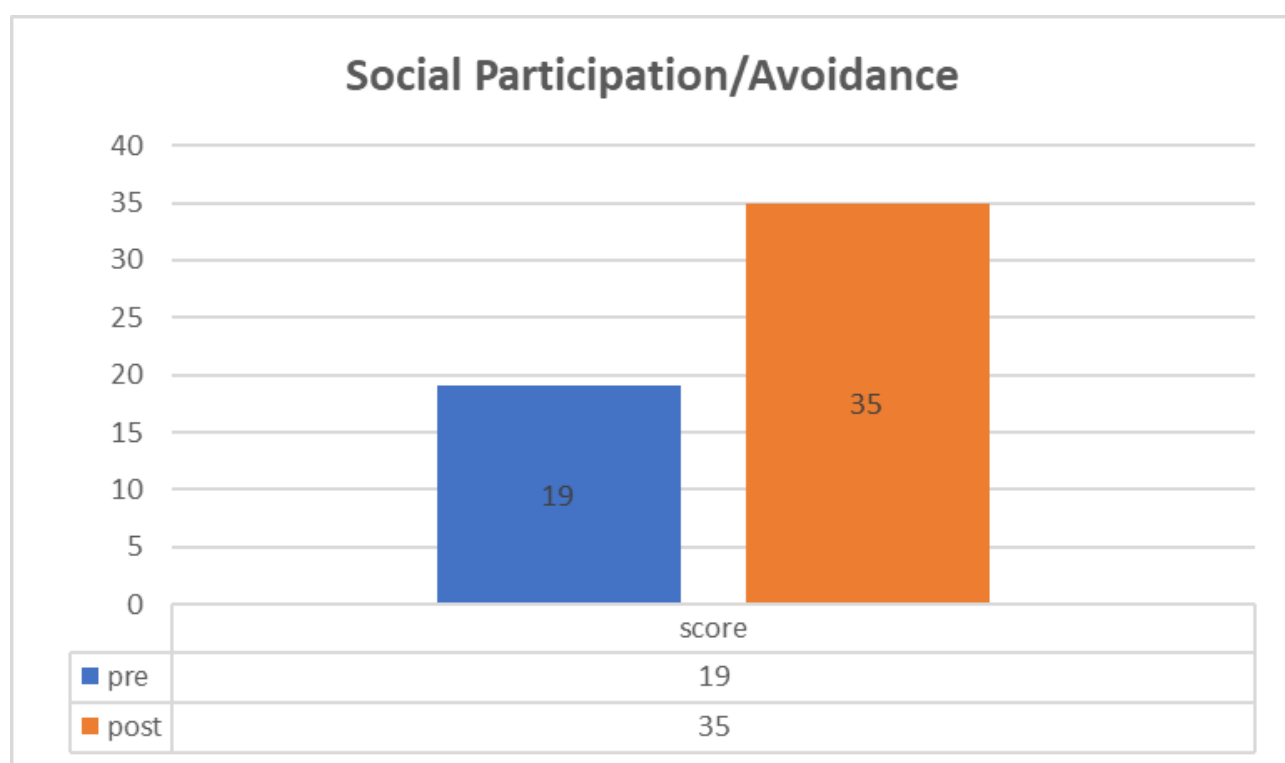

Bar chart 4: Social Participation / Avoidance factor (Total score of Pre \& Post-reading) 
Regarding the factor that assesses the detrimental social behaviors, that is, unacceptable social behaviors that lead to unsuccessful social interactions, it was noticed that the score was equal to 16.00, with the highest possible being $(\mathrm{H}=27.00)$ in the initial evaluation. The questions with the highest score were the statements "The student does not get involved in unacceptable social behaviors", "Does not experiences negative peer interactions" and "Does not make inappropriate comments". On the contrary, the questions with the lowest score were the statements "Does not exhibit poor timing with his/her social initiations", "Does not misinterpret others' intentions", "Recognizes signs that a conversation is over", "Does not end his conversations abruptly" and "Does not change the subject of a conversation by directing it towards his own interests". In the final evaluation, the score was equal to 19.00. The questions with the highest score were the statements "The student is not manipulated by peers", "The student does not have negative experiences from his relationships with his peers", "Does not get involved in unacceptable social behaviors", "Does not make inappropriate comments" and "Does not exhibit poor timing with his/her social initiations". On the contrary, the questions with the lowest score were the statements "The student does not misinterpret others' intentions", "Does not change conversation topic to fit self-interests", "Fails to read cues to terminate conversations" and "Does not end conversations abruptly". (Bar chart 5 \& $6)$.

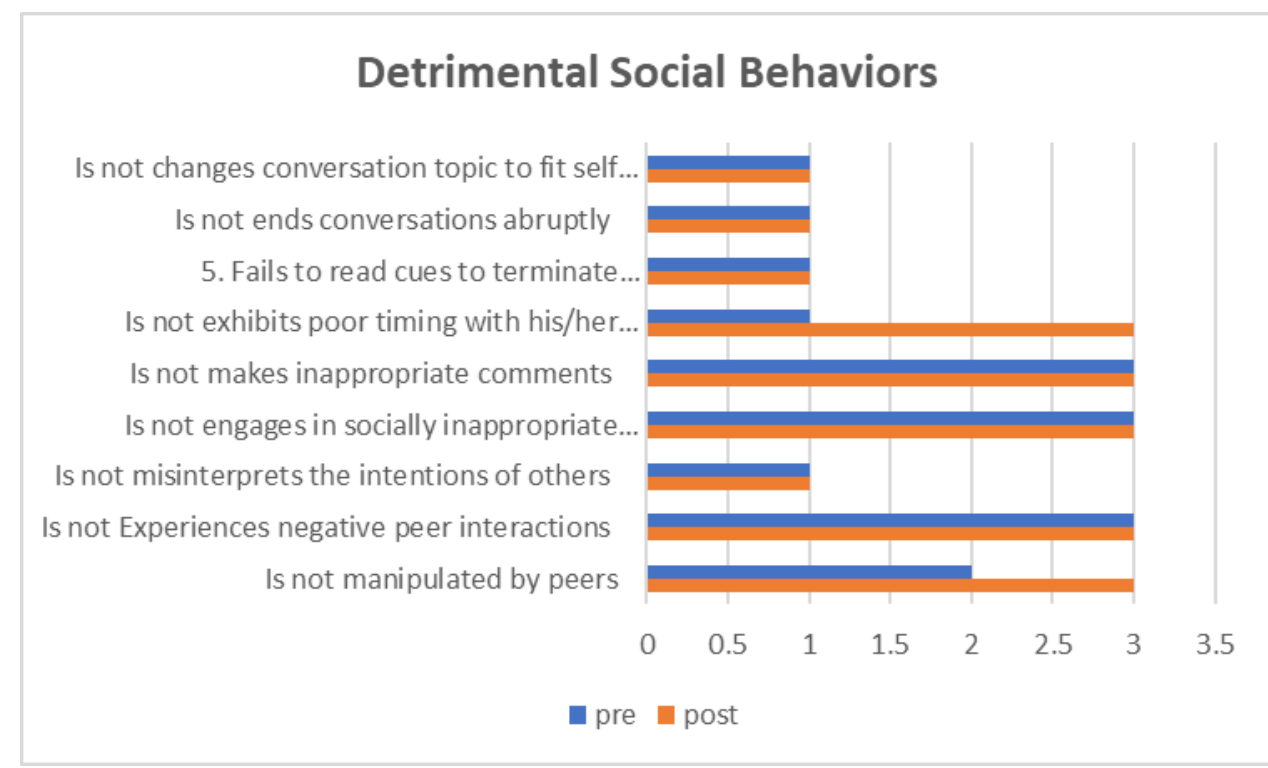

Bar chart 5: Detrimental social behaviors factor (Pre \& Post-reading) 


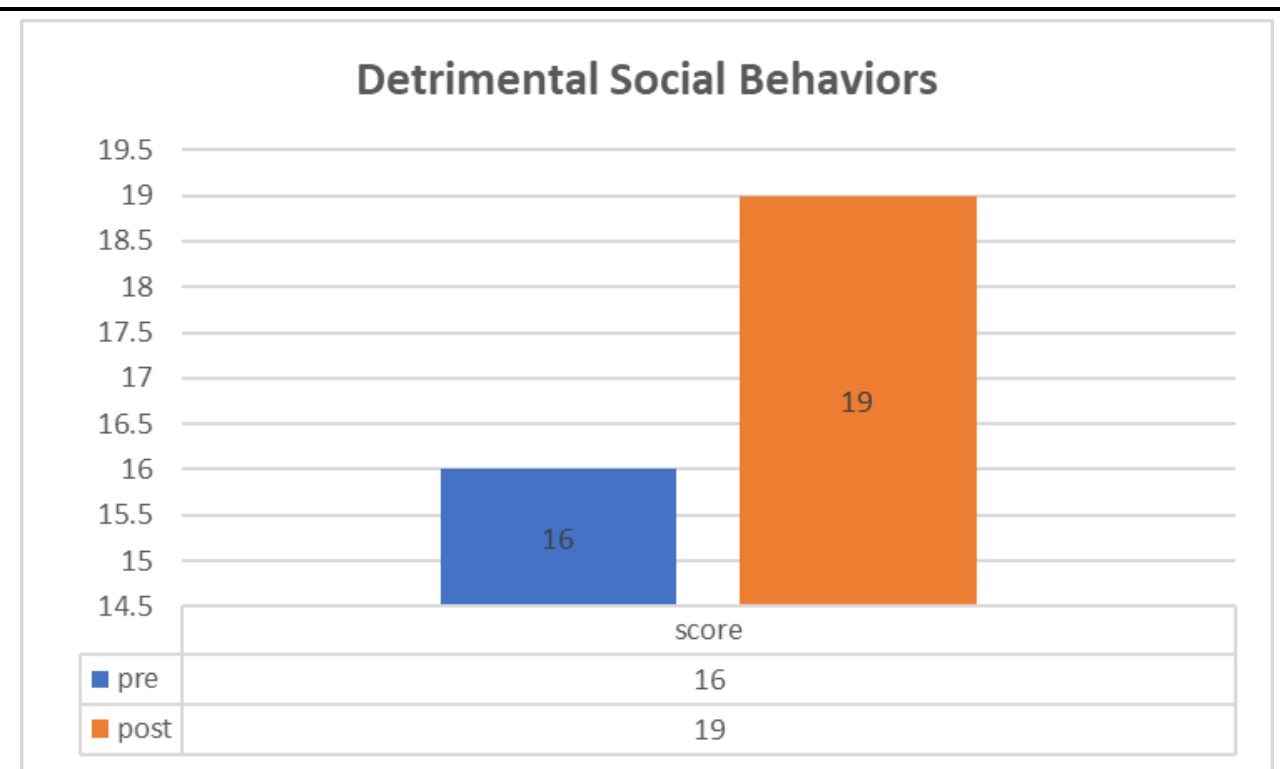

Bar chart 6: Detrimental social behaviors factor (Total score of Pre \& Post-reading)

To sum up, regarding the initial evaluation, the derived score from the sum of the three factors was $(\mathrm{H}=70)$, with the highest possible score being $(\mathrm{H}=147)$. This element indicated that the student with ASD was at a low level of social functionality, did not display social reciprocity skills, and displayed poor participation skills in social interactions. However, the student did not involve himself in unacceptable social behaviors. In the final evaluation, the derived score from the sum of the three factors was $(\mathrm{H}=106)$. This element shows that the student with ASD improved himself in many skills, such as social reciprocity, social participation, and taking the initiatives that lead to successful social interactions (Bar chart 7).

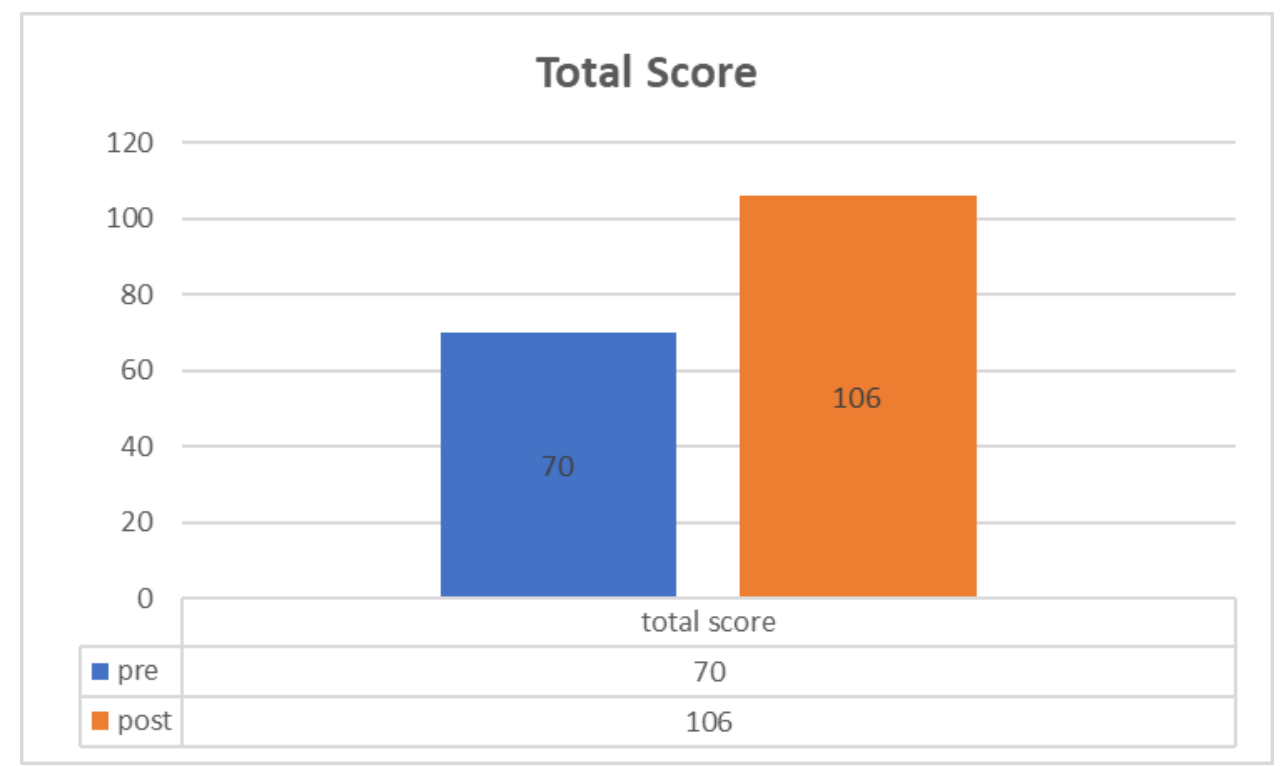

Bar chart 7: Total score (Pre \& Post-reading Comparison) 


\section{Discussion}

This paper aimed to present the impact of a PE intervention program on the regular class. It was based on suitable intervention strategies to reinforce the social interaction of a student with ASD.

According to the initial assessment, which resulted from the social skills comprehensive examination of a student with ASD based on the three factors of the questionnaire, we conclude that the student appeared to have difficulties that had to do with his social interactions, involved himself in individual activities, did not interact with peers during the structured and unstructured activities and did not allow others to help him when he was in a difficult position. Thus, this study's conclusions agree with previous studies that have demonstrated social deficits in children with ASD. In addition, it has shown their difficulty interacting and collaborating with peers to achieve a common goal (Bellini, Peters, Benner \& Hopf, 2007; Chevallier, Kohls, Troiani, Brodkin \& Schultz, 2012). However, during the post-intervention phase, the student with ASD improved many of his social skills regarding the three factors of the questionnaire.

More specifically, during the intervention program and especially by including the student in playgroups, it seemed that the student could offer his help to his classmates regarding the skills related to the social reciprocity factor. He shared stuff and could recognize compliments made by others, mainly via his participation and the praise he received from the researcher or his classmates. He recognized his classmates' facial expressions while he was watching them and was glad along with them when they achieved their goal. Also, through his inclusion in playgroups, the student took turns during games and activities. He did this with the help of more sociably capable peer players who served as models and with the encouragement from his teammates.

As previous studies have mentioned, children with ASD can be taught to interact, take the initiative, and involve themselves in social interactions through their contact with peers. Thus, their lonely stereotypical play is lessened (Laushey \& Heflin, 2000). The inclusion of the student in playgroups indicated that the student was given the opportunity to interact, was offered new experiences and familiarity with his peers, and helped in collaboration. The team games took place after some adaptations, that had been made, in the teaching method, such as the demarcation of the training space for the student to know the distance he has to cover, modulation of the equipment to help the student choose the equipment, and to reduce his stress of failure and simple rules which his teammates constantly repeated (Wolfberg, 2016). The student with ASD was happy that everyone verbally encouraged him to collaborate with them. Due to competition between teams, the students were asked to perform the activities without being noisy so that the student with ASD was not distracted. It is true that the obstacles to a successful social interaction between children with ASD and the children of typical development can be eliminated with the support and the encouragement of the latter during play and at the same time create a new friendly relationship through activities (Choi-Schonell, 2000). 
The researcher constantly encouraged the rest of the children on the specific team to tactfully involve the student in group activities, direct him and help him verbally or kinesthetically. However, the ascertainment that the student continues not to empathize with the problems others face and does not care about his classmates' interests agrees with previous studies which mentioned that $80 \%$ of the children with ASD have not developed the Theory of Mind and that is the reason they face difficulties in activities that require an understanding of how others think and being aware of others feelings and intentions. As a result, their behavior is characterized «eccentric» (Macintosh \& Dissanayake, 2006).

Regarding the concluding readings and the majority of the questions, the student displayed the most significant improvement as far as the social participation/avoidance factor is concerned. Regarding the initial evaluation, the student seemed to have positive experiences from his relations with his classmates since all of his classmates always tried to include him in the activities and help him. However, at first and most of the time, he involved himself in individual activities, did not interact with his classmates during the structured and unstructured activities, and did not allow others to help him when he was in a difficult position. These findings match the results of the study of Chevallier and his partners (2012). In the aforementioned study, the children with ASD are not interested in keeping friendly relationships or develop a positive image for themselves in their social circle and do not take the initiative to invite peers to participate jointly in activities (Chevallier et al., 2012). However, through social skills improvement programs and the use of intervention techniques in the PE lesson, just like in our research study, the student with ASD showed a greater level of interaction and participation when his classmates invited him to take part in activities along with them and allowed others to help him when there was a need which helped improve the final readings to a great degree (Cotungo, 2009).

There was one more intervention strategy that was applied and helped. That was the participation and support of the student by an adult. Specifically, the student could remain and participate successfully in every activity of each lesson with the help of the researcher. The verbal and kinesthetic guidance that was given to him helped the student carry out and understand the rules of each activity and look happy and content with the results of his efforts. The variants of the exercises also helped. Through the exercises' visualization, the student was asked to choose the level he thought he would be better at. Naturally, he chose the most challenging level, just like his classmates did. The use of auditory stimuli was also significant. They thrilled the student and marked the beginning and the end of each activity. When he knew he would make it, he sought verbal reward and anticipated it. The researcher's support was to help the student stay focused on his goal, provide all the necessary adjustments regarding the environment, help him increase his understanding, minimize social frustration, limit behavioral problems, and make the student's with ASD work easy (Robertson, Chamberlain \& Kasari, 2003).

The following intervention strategy was teaching in couples, which is based on the behavioral principles and social theory of learning. It is an intervention for developing 
social skills, increasing significantly the interaction between the student with ASD and his peers who have been methodically taught for this reason (Sperry, Neitzel, \& Engelhardt-Wells, 2010). At the same time, another technique was applied, that of the provision of a model to imitate (peer-modeling) (Neitzel, 2008). During this technique, the student watched what his classmates were doing and tried to imitate them. All this time, his classmates supported and encouraged him.

For this reason, during the semi-structured interview of the two instructors in the pre-intervention phase, we had made sure that the student with ASD could participate in group activities imitating others as long as his attention was not disrupted due to stereotypical moves and external noises. The exercises in couples and the guidance of pictures and transmission cards that led from one station to the other indicated that the student improved his proximity and eye contact. These exercises provided the student with chances to build friendly relationships and interact with all of his classmates (starting with one or two close to him), who reinforced his self-esteem by offering encouragement and feedback (Harper, Symon, \& Frea, 2008; Nelson, McDonnell \& Johnston, 2007).

Furthermore, it is worth pointing out the find that matches a previous study. According to the find, before the intervention activity, typically developing children were asked to help this particular student either kinesthetically or verbally. They responded enthusiastically and to a great extent (Choi-Schonell, 2000). During this impeccable collaboration, the part of the researcher has been a great help. She gave specific instructions to the peers so as to keep trying and catch the attention of the student with ASD, use simple and clear language when talking to the student with ASD, reward him (verbally) every time he performed and participated in an activity with them so that the student with ASD could form an opinion whether a behavior is appropriate, acceptable and suitable (Nelson, McDonnell \& Johnston, 2007).

In the initial evaluation, regarding the factor that had to do with detrimental social behaviors, which directly lead to unsuccessful social interactions, the student seems not to be involved in unacceptable social behaviors and does not display inappropriate behaviors like hostility, and that is the reason he keeps having excellent relations with his classmates (Goodman \& Williams, 2007; Matson \& Wilkins, 2007). Specifically, even though he does not often express the desire to socialize with his peers, at the same time, he does not display unacceptable social behaviors, thus reducing the possibility of involving himself in interactions with the rest of his classmates. These results match both the answers of the semi-structured interview with the two instructors and previous studies. The two instructors pointed out that the student does not display behavioral problems and previous studies mention that since the children with ASD do not display detrimental social behaviors, they achieve bigger success in the field of effective interaction with others, provided that the student is helped to develop social and communicative skills in the context of co-education (Syriopoulou-Dellie, Agaliotis \& Papaefstathiou, 2016; Simpson, De Boer- Ott \& Miles, 2003). 
However, regarding this specific factor, the student got better at taking the initiative related to his interactions. The intervention strategies that were applied during the implementation of the intervention program, such as the student's inclusion in playgroups and teaching in couples with the provision of a model, helped to do this. In this case study, the intervention techniques that were applied during the PE lesson and the supporting educational material, and the adaptations in the curriculum's activities highlighted the success of co-education in the lesson of Physical Education and helped the student with ASD to interact with his classmates and instructors in the context of the general classroom.

\section{Conclusion}

This research study was a case study. For this reason, it is not easy to generalize the results to every child on the autistic spectrum because of the fluctuations in the symptoms and the characteristics that this specific population displays. However, we consider that the results concerning the student are pretty representative for children with moderate functional autism, and we can form an overall view on this specific disorder.

In conclusion, throughout the implementation of the intervention program, the student with ASD developed a good relationship with his classmates, improved his participation in the PE lesson, improved his social reciprocity through interaction and cooperation with his peers. The fact that the student does not show inappropriate behaviors continues to be a very positive fact. And that is the reason he keeps having excellent relations with his classmates. As a general conclusion, we can state that, during the implementation phase of the intervention program, the student with ASD seems to have made progress as far as his behavior is concerned. He learned to ask for others' attention, obeyed the rules that the PE teacher applies, and wished for his participation in activities and games without the help of the parallel support teacher. Without a doubt, autism loneliness is one of the main characteristics of autism. That is why several times during the breaks, the students desired to be alone. This case study showed that the support of the Adapted Physical Education teachers to the Physical Education teachers makes the former's work easier since their collaboration improves co-education and leads to successful management of the class and in the implementation of more targeted courses (Nelson, McDonnell \& Johnston, 2007).

\section{Acknowledgement}

The authors certify that they have no commercial associations (e.g., consultancies, stock ownership, equity interest, patent/licensing arrangements, etc.) that might pose a conflict of interest in connection with the submitted article.

\section{Conflicts of interest}

The authors declare that there are no conflicts of interest. 


\begin{abstract}
About the Author(s)
Maria Markaki, Undergraduate Student, Department of Physical Education and Sport Science, University of Thessaly, Greece.

Nikoleta Chyta, Special Education Teacher, Primary Education, Athens, Greece.

Georgia Maggouritsa, Permanent Teaching Staff, Department of Physical Education and Sport Science, University of Thessaly, Greece.

Dimitrios Kokaridas, Associate Professor, Department of Physical Education and Sport Science, University of Thessaly, Greece.
\end{abstract}

\title{
References
}

Ainscow, M., Dyson, A., \& Weiner, S. (2013). From Exclusion to Inclusion: ways of responding in schools to students with special educational needs. Manchester: CFBT Education Trust.

Ali, S., \& Frederickson, N. (2006). Investigating the evidence base of social stories. Educational Psychology in Practice, 22(4), 355-377.

American Psychiatric Association (2013). Diagnostic and statistical manual of mental disorders (DSM-5®). American Psychiatric Association Publishing.

Bellini, S., \& Hopf, A. (2007). The development of the autism social skills profile: A preliminary analysis of psychometric properties. Focus on Autism and Other Developmental Disabilities, 22(2), 80-87.

Bellini, S., Peters, J. K., Benner, L., \& Hopf, A. (2007). A meta-analysis of school-based social skills interventions for children with autism spectrum disorders. Remedial and Special Education, 28(3), 153-162.

Booth, T., \& Ainscow, M. (2011). Index for Inclusion: Developing Learning and Participation in Schools. Centre for Studies on Inclusive Education, Bristol.

Chan, J. M., Lang, R., Rispoli, M., O’Reilly, M., Sigafoos, J., \& Cole, H. (2009). Use of peermediated interventions in the treatment of autism spectrum disorders: a systematic review. Research in Autism Spectrum Disorders, 3(4), 876-889.

Chevallier, C., Kohls, G., Troiani, V., Brodkin, E. S., \& Schultz, R. T. (2012). The social motivation theory of autism. Trends in Cognitive Sciences, 16(4), 231-239.

Choi-Schonell, S. (2000). Let's play: Children with autism and their play partners together. Paper presented at the International Special Education Congress 2000: Including the Excluded, University of Manchester.

Cotugno, A. J. (2009). Social competence and social skills training and intervention for children with autism spectrum disorders. Journal of Autism and Developmental Disorders, 39, 1268-1277.

Cox, A. W., Brock, M. E., Odom, S. L., Rogers, S. J., Sullivan, L. H., Tuchman- Ginsberg, L., \& Collet-Klingenberg, L. (2013). National Professional Development Center on ASD: An emerging national educational strategy. Autism Services Across America, 249-266. 
Faras, H., Al Ateeqi, N. \& Tidmarsh, L. (2010). Autism Spectrum Disorders. Annals of Saudi Medicine, 295, 30-34.

Ferreira, J. P., Andrade Toscano, C. V., Rodrigues, A. M., Furtado, G. E., Barros, M. G., Wanderley, R. S., \& Carvalho, H. M. (2018). Effects of a Physical Exercise Program (PEP-Aut) on Autistic Children's Stereotyped Behavior, Metabolic and Physical Activity Profiles, Physical Fitness, and Health-Related Quality of Life: A Study Protocol. Front. Public Health 6, 47.

Goodman, G., \& Williams, C.M. (2007). Interventions for increasing the academic engagement of students with autism spectrum disorders in inclusive classrooms. Teaching exceptional children, 39(6), 53-61.

Harper, C. B., Symon, J. B., \& Frea, W. D. (2008). Recess is Time-in: Using Peers to Improve Social Skills of Children with Autism. Journal of Autism and Developmental Disorders, 38 (5), 815-826.

Hendricks, D. R., \& Wehman, P. (2009). Transition from school to adulthood for youth with autism: Review and recommendations. Focus on Autism and Developmental Disabilities, 24(2), 77-89.

Jordan, R. (2005b). Autistic spectrum disorders', in A. Lewis \& B. Norwich (eds) Special Teaching for Special Children? Pedagogy for Special Educational Needs. Milton Keynes: Open University Press.

Klavina, A., Jerlinder, K., Kristén, L., Hammar, L. \& Soulie, T. (2014). Cooperative Oriented Learning in Inclusive Physical Education. European Journal of Special Needs Education, 9(2), 119-134.

Laushey, K. \& Heflin, L. J. (2000). Enhancing social skills of kindergarten children with autism through the training of multiple peers as tutors. Journal of Autism and development Disorders, 30, 183-193.

Lee, J., \& Vargo, K. K. (2017). Physical Activity into Socialization: A Movement-based Social Skills Program for Children with Autism Spectrum Disorder. Journal of Physical Education, Recreation \& Dance, 88(4), 7-13.

Liu, T., Kaarengala, V., \& Litchke, L. G. (2019). Motor competence and social function in children with autism spectrum disorder. Journal of Physical Education and Sport, 19(1), 521-526.

Macintosh, K. \& Dissanayake, C. (2006). Social Skills and Problem Behaviours in School Aged Children with High-Functioning Autism and Asperger's Disorder. Journal of Autism and Developmental Disorders, 36(8), 1065-76.

Matson, J.L, \& Wilkins, J. (2007). A critical review of assessment targets and methods for social skills excesses and deficits with autism spectrum disorders. Research in Autism Spectrum Disorders, 1, 28-37.

Neitzel, J. (2008). Overview of peer-mediated instruction and intervention for children and youth with autism spectrum disorders. Chapel Hill, NC: National Professional Development Center on Autism Spectrum Disorders, FPG Child Development Institute, The University of North Carolina. 
Nelson, C., McDonnell, A., \& Johnston, S. (2007). Keys to play: A strategy to increase the social interactions of young children with autism and their typically developing peers. Education and Training in Developmental Disabilities, 42(2), 165-81.

Pan, C. Y. (2014). Motor proficiency and physical fitness in adolescent males with and without autism spectrum disorders. Autism, 18, 156-165.

Papaefstathiou, E. \& Syriopoulou-Delli, C. (2014). Assessment of social skills in students with Autistic Spectrum Disorder. $4^{\text {th }}$ National Conference of Education Sciences, 789-799.

Robertson, K., Chamberlain, B., \& Kasari, C. (2003). General education teachers' relationship with included students with autism. Journal of Autism and Developmental Disorders, 33, 123-130.

Reynhout, G., \& Carter, M. (2006). Social stories for children with disabilities. Journal of Autism and developmental Disorders, 36, 445-449.

Simpson, R. L., DeBoer-Ott, S. R. \& Smith-Myles, B. (2003). Inclusion of learners with autism spectrum disorders in general education settings. Topics in language Disorders, 23 (2), 116-33.

Sherratt, D. (2002). Developing pretend play in children with autism: A case study. Autism, 6(2), 169-179.

Sperry, L., Neitzel, J., \& Engelhardt-Wells, K. (2010). Peer-mediated instruction and intervention strategies for students with autism spectrum disorders. Preventing School Failure, 54, 256-264.

Srinivasan, S. M., Pescatello, L. S., \& Bhat, A. N. (2014). Current perspectives on physical activity and exercise recommendations for children and adolescents with autism spectrum disorders. Physical Therapy, 94(6), 1-46.

Syriopoulou-Delli, C., Agaliotis, I. \& Papaefstathiou, E. (2016). Social skills characteristics of students with autism spectrum disorder. International Journal of Developmental Disabilities, 1-11.

Tutt, R., Powell, S., \& Thornton, M. (2006). Educational approaches in autism: what we know about what we do. Educational Psychology in Practice, 22(1), 69-81.

Tyler, K., MacDonald, M., \& Menear, K. (2014). Physical Activity and Physical Fitness of School-Aged Children and Youth with Autism Spectrum Disorders. Autism Research and Treatment, 1-6.

Walton, K. \& Ingersoll, B. (2013). Expressive and receptive fast-mapping in children with autism and typical development: The influence of orienting cues. Research in Autism Spectrum Disorders, 7, 687-698.

Wolfberg, P. J. (2016b). Integrated Play Groups: Supporting children with autism in essential play experiences with typical peers. In L. Reddy, C. Schaefer, \& L. File-Hall (Eds), Empirically-based play interventions for children (Second Edition) American Psychological Association. 
Creative Commons licensing terms

Authors will retain the copyright of their published articles agreeing that a Creative Commons Attribution 4.0 International License (CC BY 4.0) terms will be applied to their work. Under the terms of this license, no permission is required from the author(s) or publisher for members of the community to copy, distribute, transmit or adapt the article content, providing a proper, prominent and unambiguous attribution to the authors in a manner that makes clear that the materials are being reused under permission of a Creative Commons License. Views, opinions and conclusions expressed in this research article are views, opinions and conclusions of the author(s). Open Access Publishing Group and European Journal of Special Education Research shall not be responsible or answerable for any loss, damage or liability caused in relation to/arising out of conflict of interests, copyright violations and inappropriate or inaccurate use of any kind content related or integrated on the research work. All the published works are meeting the Open Access Publishing requirements and can be freely accessed, shared, modified, distributed and used in educational, commercial and non-commercial purposes under a Creative Commons Attribution 4.0 International License (CC BY 4.0). 